\title{
POLYMORPHIC DELETIONS OF GLUTATHIONE S-TRANSFERASES M1, T1 AND BLADDER CANCER RISK IN ALGERIAN POPULATION
}

\author{
AHMED HIRECHE ${ }^{1 *}$, NAOUEL CHAOUI-KHEROUATOU ${ }^{1}$, ASMA RIBOUH ${ }^{1}$, NOUREDDINE ABADI ${ }^{2}$, MING-JUN SHI ${ }^{3}$, \\ DALILA SATTA $^{1}$
}

${ }^{1}$ Department of Animal Biology, Laboratory of Cellular and Molecular Biology, University Constantine 1, Constantine 25000, Algeria. ${ }^{2}$ Laboratory of Biology and Molecular Genetic, University Constantine 3, Constantine 25000, Algeria. ${ }^{3}$ Laboratory of Molecular Oncology, UMR 144, Institut Curie, 75005 Paris, France. Email: hireche.ahmed@yahoo.fr

Received: 07 March 2018, Revised and Accepted: 12 April 2018

\begin{abstract}
Objective: Glutathione S-transferase mu 1 (GSTM1) and GST theta 1 (GSTT1) genes are two xenobiotic metabolizing genes in Phase II of the detoxification process. The polymorphisms of GSTM1, GSTT1 genes, and smoking are involved in many cancers such as bladder cancer. Our aim was to assess the role of smoking status and GSTM1 and GSTT1 null genotypes in bladder cancer development in Algerian population.
\end{abstract}

Methods: The current case-control study included 175 bladder cancer patients and 188 controls matched for age, gender, and ethnic origin. The GSTM1 and GSTT1 genotypes were determined by multiplex polymerase chain reaction using blood genomic DNA. Possible associations of stage and grade with the obtained genotypes were also tested.

Results: A significant associations were observed between bladder cancer risk and tobacco smoke (p value: $\mathrm{p}=1.21 \mathrm{E}-08$ ), GSTM1 null genotype $(\mathrm{p}=0.018)$, GSTT1 null genotype ( $\mathrm{p}=0.009)$, and GSTM1/GSTT1-double null genotype $(\mathrm{p}=0.001)$. The combined effect of smoking and testing deletions increased the risk of bladder cancer and the most important risk was observed among smokers carrying GSTM1/GSTT1-double null genotype $(\mathrm{p}=1.09 \mathrm{E}-05)$. No significant association was shown between stage and grade of bladder cancer and the testing genotypes.

Conclusion: This study indicated that smoking, GSTM1 null, GSTT1 null, and GSTM1/GSTT1-double null genotypes individually represent a risk factor for bladder cancer in Algerian population. The interaction smoking gene increased the risk considerably. In fact, it is suggested that patients with cigarette smoking habit and combined GSTM1 and T1 genes deletion might be at increased risk of bladder cancer.

Keywords: Glutathione S-transferase mu 1, Glutathione S-transferase theta 1, Smoking, Bladder cancer.

(C) 2018 The Authors. Published by Innovare Academic Sciences Pvt Ltd. This is an open access article under the CC BY license (http://creativecommons. org/licenses/by/4. 0/) DOI: http://dx.doi.org/10.22159/ajpcr.2018.v11i5.25673

\section{INTRODUCTION}

Cancer is currently estimated to be a major cause of deaths worldwide [1]. Urothelial bladder cancer is one of the commonly occurring cancers [2]. It is the $7^{\text {th }}$ most commonly diagnosed cancer in males and the $17^{\text {th }}$ in females worldwide. Global estimates suggest that there are annually 330400 bladder cancer cases with 123,100 related deaths in the word [3].

In North African men, bladder cancer is the most common cancer after liver and lung cancers, accounting an annual estimated incidence of 11,225 with 5489 deaths [3]. Between 2006 and 2010, the incidence for Algerian men were $10.3 / 100,000$ person-years, this represents $9.1 \%$ of the global cancer incidence in Algeria [4].

Bladder cancer can be muscle-invasive or non-invasive and classified as high-grade or low-grade tumor, respectively [5]. The risk of this disease increases with advancing age and most cases are diagnosed above 65 years of age [6]. The incidence is 5-7 times higher in males than in females in Algeria and North Africa [3,4].

It is admitted that the primary prevention of this deadly disease needs first of all understanding the etiology and determining the risk factors.

Smoking is the most well-established risk factor for bladder cancer in both sexes [5,7], with the risk among smokers reported to be approximately fourfold that among non-smokers [7].

The combustion of tobacco releases at least at 69 known carcinogens which have been directly implicated as mutagens causing bladder cancer $[8,9]$.
Following smoking, occupational exposure to aromatic amines and polycyclic aromatic hydrocarbons (PAHs) are other important risk factors [10]. Increasing evidence suggests a significant influence of genetic polymorphism of xenobiotic-metabolizing enzymes which could increase susceptibility to various environmental and clinical conditions. The balance between activation and detoxification of carcinogens affects the amount of DNA damage that occurs in cells [11].

A large family of enzymes has been encoded by glutathione-Stransferases (GSTs) multigene and plays a vital role in the mechanism of cellular detoxification [9,12]. Until now, human cytosolic GST superfamily contains at least 16 genes subdivided into eight distinct classes designated as: (pi), (alpha), (sigma), (mu), (theta), (kappa), (omega), and (zeta), which are encoded by the GSTA, GST mu (GSTM), GSTK, GSTO, GSTP, GSTS, GST theta (GSTT), and GSTZ genes [11]. They catalyze different reactions with bladder cancer carcinogens such as aminobiphenyls and PAHs [13]. Functional polymorphisms have been identified in the GSTM1, GSTT1, GSTP1, and GSTA1 [11,14]. In recent years, studies of GSTS have revealed new roles for some of the members of this family. It has been demonstrated that GSTs of classes (alpha), (mu), and (pi) are involved in cell proliferation, differentiation, and control of cell death through interactions with special signaling proteins [15].

It was reported that both GSTM1 and GSTT1 genes exhibit deletion polymorphisms. Homozygous deletions of these genes resulted in null genotypes which results in a lack of enzyme activity $[9,12]$. This information suggests that these mutations may interfere and affect the susceptibility to many malignant tumors as cervical, laryngeal, oral, and bladder cancer $[9,12]$. 
Positive association of GSTM1 and GSTT1 deletion polymorphism and bladder carcinoma was found among many populations [16]. However, data related to a genetic status of GSTM1 and GSTT1 and their association to bladder cancer is not available in Algerian population. Therefore, the aim of this current study was first to examine the association between GSTM1 and GSTT1 genes variants and bladder cancer risk through a case-control study in Algerian population. Then, we evaluated the differential as well as the combined effect of selected variants according to tobacco smoking in the onset and development of bladder carcinoma. Finally, we tried to establish an association between these two studied genes and clinicopathologic characteristics of bladder cancer.

\section{METHODS}

\section{Subjects}

The study population consisted of 175 patients with bladder cancer and 188 healthy controls. Cases were recruited between September 2014 and May 2016 from Central Hospital University of Tizi-Ouzou (Urology department) and Daksi renal Clinic of Constantine (Urology department). All were from North of Algeria, aged between 22 and 90 years. More than $92 \%$ of them were men. All patients were confirmed by clinical histopathology and staged according to the tumor/node/metastasis staging system of the Union International Contre le Cancer (UICC; 1997). Tumors were graded according to the World Health Organization 1973 classification.

The control group consisted of unrelated healthy subjects without a history of malignant disease who were approximately matched for gender proportion, geographic origin, and age range, to those in the case group. A detailed questionnaire was elaborated and used to obtain study information's, and under informed consent, peripheral blood samples were collected into tubes with EDTA (pH 8).

\section{DNA extraction}

Genomic DNA was extracted from peripheral leukocytes using sodium chloride $(\mathrm{NaCl})$ method. The quality and quantity of DNA were determined, respectively, by agarose gel electrophoresis and spectrophotometric analysis using nanodrop. DNA was diluted to $10 \mathrm{ng} / \mathrm{ml}$ and stored at $-20^{\circ} \mathrm{C}$ for further use as a template.

Genotyping of the GSTM1 and GSTT1 using multiplex polymerase chain reaction (PCR)

The screening of GSTM1 and GSTT1 genes was performed by multiplex PCR methodology. Briefly, the PCR was carried out in $25 \mu$ mixture containing 50 ng of DNA using DNA Polymerase Kit: HotStarTaq DNA polymerase-QIAGEN ( $4 \mu \mathrm{l}$ buffer $\times 1,8 \mathrm{mM}$ of deoxynucleosides S-triphosphates, $2 \mathrm{U} / \mu \mathrm{l}$ Taq polymerase, and $2.5 \mathrm{mM}$ of each primer).

The paired primers for GSTM1 were:

5'-GAACTCCCTGAAAAGCTAAAGC-3' and 5'-GTTGGGCTCAAATATACGGT GG-3' [12].

The paired primers for GSTT1 were:

\section{5'-TTCCTTACTGGTCCTCACATCTC-3' and 5'-TCACCGGATCATGGCCACCA- $3^{\prime}[12]$.}

The paired primers for $\beta$-globulin were:

5'-ACACAACTGTGTTCACTAGC-3' and 5'-CAACTTCATCCACGTTCACC$3^{\prime}[12]$.

$\beta$-globulin was used as an internal control, confirming successful PCR amplification to ensure that the GSTM1 null and GSTT1 null were due to the deletion allele of the GSTS and not because of the failure of the PCR.

Cycling conditions were as follows: Initial preheat $95^{\circ} \mathrm{C}$ for $10 \mathrm{~min}$, 35 cycles of $94^{\circ} \mathrm{C}$ for $1 \mathrm{~min}, 60^{\circ} \mathrm{C}$ for $45 \mathrm{~s}$, and $72^{\circ} \mathrm{C}$ for $1 \mathrm{~min}$. The final extension was done at $72^{\circ} \mathrm{C}$ for $10 \mathrm{~min}$. The amplified products were subjected to electrophoresis on $2 \%$ agarose gel, stained with ethidium bromide, and visualized under ultraviolet light. The GSTM1 fragment was 230 bases pairs (bp), the GSTT1 was $480 \mathrm{bp}$, and the $\beta$-globulin fragment was $110 \mathrm{bp}$ in size.

\section{Statistical analysis}

Relative risks were estimated by calculating the odds ratios (OR) with 95\% confidence intervals (CI) at the 0.05 significance level. OR were calculated using $\mathrm{R}$ software version 3.2.3. $\mathrm{p}<0.05$ were considered statistically significant.

\section{RESULTS}

\section{Characteristics of the study population}

Relevant characteristics of cases and controls are given in Table 1. There are more male than female cases $(92.6 \%$ vs. $7.4 \%)$ with a sex ratio of 12:1. The mean age of bladder cancer patients and controls were similar, $60.77 \pm 13.21$ years (range $22-90$ ) and $59.56 \pm 14.02$ years (range 22-89), respectively. 80\% of bladder cancer patients were more than 50 years of age. Smoking was more widespread among patients with bladder cancer 122/175 (69.7\%) than controls 74/188 (39.4\%) which it recalled that they had been taken randomly $(\mathrm{p}=1.21 \mathrm{E}-08)$. Of the 175 cancer patients, $16 \%$ had tumors with Grade I, 25.1\% Grade II, and $58.9 \%$ Grade III. $19.4 \%$ had a Ta stage, $48.6 \%$ had a T1, $23.4 \%$ had a $\mathrm{T} 2$, and $8.6 \%$ had a $\mathrm{T} 3$ stage or more.

GSTs genotypes, bladder cancer susceptibility, and interactions with smoking

GSTs genotypes frequencies and their relation to bladder cancer risk

GSTM1 null genotype (M1-) was more frequent than GSTT1 null genotype (T1-). Their frequencies were $57.1 \%$ and $39.4 \%$, respectively, in bladder cancer patients compared to $44.7 \%$ and $26.6 \%$ respectively in healthy controls (Table 2). These results show a significant association between the GSTM1 null genotype and risk of bladder cancer ( $\mathrm{p}=0.018)$. GSTT1 null genotype was also associated with greater risk toward this type of cancer $(\mathrm{p}=0.009)$.

Combined GSTM1 and GSTT1 genotypes and bladder cancer risk The analysis of combined GSTM1 and GSTT1 genotypes revealed that all combinations were significantly associated with increased bladder cancer risk. As presented in Table 2, our results show clearly that the combinations between GSTM1 and GSTT1 genotypes increase the OR values and decrease the $\mathrm{p}$ value. The highest $\mathrm{OR}$ was observed for GSTM1/GSTT1-double null genotype (OR=2.9; CI: 1.44-6; $\mathrm{p}=0.001)$.

\section{Association of GSTs genotypes and smoking status with bladder} cancer risk

The stratification of patients and controls according to GSTs genotypes and tobacco status is depicted in Table 2. The results indicated any statistically significant association between GSTM1 null, GSTT1 null genotypes, or possible combined GSTM1/GSTT1 genotypes with bladder cancer risk among never smoker group.

However, among current or prior smokers group, all tested genotypes were revealed as risk genotypes except for combined GSTM1 positive/ GSTT1 positive $(\mathrm{p}=0.17)$.

It is important to note that the interaction of smoking and one GSTs null genotypes increase the risk considerably, $(\mathrm{OR}=6.7$; CI: 2.8-16.8; $\mathrm{p}=1.33 \mathrm{E}-06)$ for GSTM1 null genotype and (OR=6.9; CI: 2.3-22.7; $\mathrm{p}=0.0001$ ) for GSTT1 null genotype. Smokers with GSTM1/GSTT1-double null genotypes have a most important risk for developing bladder cancer (OR=7.9; CI: 2.8-24.4; $\mathrm{p}=1.09 \mathrm{E}-05)$ when compared to a reference group of non-smokers with the GSTM1 positive/GSTT1 positive.

Relationship between GSTs genotypes and clinicopathological parameters

The associations of GSTM1, GSTT1, or combined GSTM1/GSTT1 genotypes with tumor grades or stages of bladder cancer were not seen (data not shown). 
Table 1: Characteristics of the study population

\begin{tabular}{|c|c|c|c|c|c|}
\hline Parameters & Controls (\%) & Cases (\%) & OR & CI & p value \\
\hline \multicolumn{6}{|l|}{ Gender } \\
\hline Male & 169 (89.9) & $162(92.6)$ & - & - & 0.37 \\
\hline Female & $19(10.1)$ & $13(7.4)$ & - & - & \\
\hline \multicolumn{6}{|l|}{ Age (years) } \\
\hline$<50$ & $43(22.9)$ & $35(20)$ & - & - & 0.5 \\
\hline$\geq 50$ & $145(77.1)$ & $140(80)$ & - & - & - \\
\hline Mean age (range) & $59.56 \pm 14.02(22-89)$ & $60.77 \pm 13.21(22-90)$ & - & - & - \\
\hline Never smoker & $114(60.6)$ & $53(30.2)$ & - & - & - \\
\hline Current or prior smoker & $74(39.4)$ & $122(69.7)$ & 3.55 & $229-5.48$ & $1.21 \mathrm{E}-08^{* *}$ \\
\hline \multicolumn{6}{|l|}{ Grade } \\
\hline G1 & - & $28(16)$ & - & - & - \\
\hline G2 & - & $44(25.1)$ & - & - & - \\
\hline G3 & - & $103(58.9)$ & - & - & - \\
\hline \multicolumn{6}{|l|}{ TNM stage } \\
\hline $\mathrm{Ta}$ & - & $34(19.4)$ & - & - & - \\
\hline T3 or more & - & $15(8.6)$ & - & - & - \\
\hline \multicolumn{6}{|l|}{ Recurrences } \\
\hline No & - & $83(47.4)$ & - & - & - \\
\hline Yes & - & $92(52.6)$ & - & - & - \\
\hline Cystectomy after & - & $9(5.1)$ & - & - & - \\
\hline Evolution & & & & & \\
\hline
\end{tabular}

Table 2: GSTM1, GSTT1 genotypes, and combined genes-smoking effect on bladder cancer susceptibility

\begin{tabular}{|c|c|c|c|c|c|}
\hline Genotypes & Controls (\%) & Cases (\%) & OR & CI 95\% & $p$ value \\
\hline \multicolumn{6}{|l|}{ GSTM1 } \\
\hline M1+ & $104(55.3)$ & $75(42.9)$ & - & - & - \\
\hline M1- & $84(44.7)$ & $100(57.1)$ & 1.65 & $1.09-2.5$ & 0.018 \\
\hline \multicolumn{6}{|l|}{ GSTT1 } \\
\hline $\mathrm{T} 1+$ & $138(73.4)$ & $106(60.6)$ & - & - & - \\
\hline $\mathrm{T} 1-$ & $50(26.6)$ & $69(39.4)$ & 1.8 & $1.15-2.8$ & $0.009 * *$ \\
\hline \multicolumn{6}{|c|}{ GSTM1/GSTT1 } \\
\hline $\mathrm{M} 1+/ \mathrm{T} 1-$ & $28(14.9)$ & $35(20)$ & 2.36 & $1.2-4.67$ & $0.004^{* *}$ \\
\hline M1-/T1+ & $62(33)$ & $66(37.7)$ & 2.02 & $1.2-3.39$ & $0.007^{* *}$ \\
\hline M1-/T1- & $22(11.7)$ & $34(19.4)$ & 2.9 & $1.44-6$ & $0.001^{* *}$ \\
\hline \multicolumn{6}{|c|}{ GSTM1-smoking } \\
\hline \multicolumn{6}{|c|}{ Never smoker } \\
\hline M1+ & $58(30.9)$ & $28(16)$ & - & - & - \\
\hline M1- & $56(29.8)$ & $25(14.3)$ & 0.9 & $0.45-1.86$ & 0.87 \\
\hline \multicolumn{6}{|c|}{ Current or prior smoker } \\
\hline M1- & $28(14.9)$ & $75(42.9)$ & 5.5 & $2.84-10.9$ & 3.87E-08** \\
\hline \multicolumn{6}{|c|}{ GSTT1-smoking } \\
\hline \multicolumn{6}{|c|}{ Never smoker } \\
\hline $\mathrm{T} 1+$ & $81(43.1)$ & 31 (17.7) & - & - & - \\
\hline T1- & $33(17.6)$ & $22(12.6)$ & 1.7 & $0.8-3.6$ & 0.1 \\
\hline \multicolumn{6}{|c|}{ Current or prior smoker } \\
\hline $\mathrm{T} 1+$ & $57(30.3)$ & $75(42.9)$ & 3.4 & $2-6$ & $6.96 \mathrm{E}-06^{* *}$ \\
\hline T1- & $17(9)$ & $47(26.9)$ & 7.1 & $3.4-15.4$ & $6.3 \mathrm{E}-09 * *$ \\
\hline \multicolumn{6}{|c|}{ GSTM1/GSTT1-smoking } \\
\hline \multicolumn{6}{|c|}{ Never smoker } \\
\hline $\mathrm{M} 1+/ \mathrm{T} 1+$ & $38(20.2)$ & $14(8)$ & - & - & - \\
\hline $\mathrm{M} 1+/ \mathrm{T} 1-$ & $20(10.6)$ & $14(8)$ & 1.88 & $0.7-5.2$ & 0.2 \\
\hline M1-/T1+ & $43(22.9)$ & $18(10.3)$ & 1.1 & $0.5-2.8$ & 0.8 \\
\hline M1-/T1- & $13(6.9)$ & $7(4)$ & 1.4 & $0.4-5$ & 0.56 \\
\hline \multicolumn{6}{|c|}{ Current or prior smoker } \\
\hline $\mathrm{M} 1+/ \mathrm{T} 1+$ & $38(20.2)$ & $26(14.9)$ & 1.8 & $0.8-4.4$ & 0.17 \\
\hline $\mathrm{M} 1+/ \mathrm{T} 1-$ & $8(4.3)$ & $21(12)$ & 6.9 & $2.3-22.7$ & $0.0001^{* *}$ \\
\hline
\end{tabular}

GSTM1 positive (M1+), GSTM1 null (M1-), GSTT1 positive (T1+), and GSTT1 null (T1-), (**): P<0.01. GSTM1: Glutathione S-transferase mu 1, GSTT1: Glutathione

$S$-transferase theta 1, OR: Odds ratios, CI: Confidence intervals 


\section{DISCUSSION}

We have undertaken this current study to investigate the combined effect of GSTM1, GSTT1 genes polymorphism, and smoke on bladder cancer susceptibility in Algerian population.

Our case-control study revealed, first in bladder cancer group that the incidence is 12 times higher in males than in females (sex ratio 12:1). This difference in incidence is greater than those reported in previous studies among North Africans [3] and Algerian population [4]. We have also shown that cigarette smoking was a significant risk factor for bladder cancer risk (OR=3.55; CI: 2.9-5.48; $\mathrm{p}=1.21 \mathrm{E}-08$ ). More than $50 \%$ of our cases are smokers. A similar observation was made by Burger et al. [8]. Several previous studies in the world demonstrated the increased risk of bladder cancer in smokers $[5,7,16,17]$

Bladder cancer is the result of the variable combination of two determinants: Endogenous or constitutional factors and exogenous or environmental factors [6]. Genetic differences between detoxification systems may cause an increase in susceptibility to environmentally induced bladder cancer [18]. Thus, the GSTs are multigene familyrelated isozymes that involved in the detoxification of carcinogens, including PAHs present in tobacco smoke $[6,9,12,19]$. It was noted that GSTM1 null genotype is the most important factor for the reduction of total GST activity [20]. The polymorphism in the GSTT1 gene loci is also caused by a gene deletion and leads to a virtual absence of enzyme activity in individuals with the null genotype [11]. GSTM1 and GSTT1 gene polymorphisms have been associated with a wide variety of cancers including bladder cancer [9].

It is reported that the prevalence of GSTM1 null genotype varies widely from $31 \%$ to $88 \%$ in relation to ethnic origin [21]. This frequency in our studied population was $44.7 \%$ for healthy controls and $57.1 \%$ for cases which approach substantially to that given for Tunisian and Egyptian populations [22-24]. Deletion of GSTT1 loci was higher in bladder cancer patients than in controls $(39.4 \%$ vs. $26.6 \%$, respectively). These proportions were so different to that compared to other ethnic groups [25].

To investigate the impact of metabolic polymorphism in modulating bladder cancer risk susceptibility, we have compared genotypic frequencies of studied genes between individuals carrying the wildtype (GSTM1 positive, GSTT1 positive) and individuals at risk (GSTM1 null, GSTT1 null).

Our results indicate that in Algerian population the GSTM1 null genotype confers statistically a significant correlation for overall risk for bladder cancer (OR=1.65; CI: 1.09-2.5; $\mathrm{p}=0.018$ ). This finding is consistent with combined results of 26 studies represented in the meta-analysis of Zhang et al. [26], including 5029 bladder cancer cases and 6680 controls. Other more recent studies carried out in India and Pakistan have given the same result $[16,27]$. Among all studied ethnic groups, the association between GSTM1 null genotype and risk of bladder cancer was observed in Asians and Caucasians [26]. Conversely, in Tunisian and Egyptian populations results suggested that this polymorphism had no effect on risk of bladder carcinogenesis [24,28-30]. Moreover, only one Egyptian study recorded this association, but it presented a limitation of effective which was too low [31].

We also investigated the association of GSTT1 and bladder cancer. As for the GSTM1 null genotype, statistical test shows an association between the GSTT1 null genotype and urinary bladder cancer $(\mathrm{OR}=1.8$, CI: $1.15-2.8 ; \mathrm{p}=0.009)$. Our results were in agreement with a number of other studies presented in a meta-analysis of Gong et al. [19] who reported this association in Caucasians. However, no dramatically increased risk was found for other populations including North Africans [12,19,24,28,29,32], except for the study of Saad et al. [30] who suggested an increased risk with GSTT1null genotype in the Egyptian population.
Patients with combined homozygous deletion (GSTM1 null/GSTT1 null) have a greater risk (OR=2.9; CI: $1.44-6 ; \mathrm{p}=0.001)$ compared to those harboring only one deletion. This is in accordance to the results mentioned in the meta-analyses of Gong et al. [19]. This observation can be explained by the fact that the presence of the combined homozygous deletion of GSTM1 and GSTT1 genes is associated with reduction or complete loss of the enzyme activity $[12,13]$. In this context, we can suggest that the double mutated genotype may play an important role in the susceptibility of bladder cancer.

In this study, we have also compared genotypic frequencies of studied genes combined with smoking status between non-smokers carrying wild type as a reference group and individuals at risk: Smokers with one or two genetic risk factors. About GSTM1 null genotype, we found that risk is present only in smokers. However, for GSTT1 null genotype, the risk is most important in smokers than no smokers group.

The simultaneous association of both null GSTM1 and GSTT1 genotypes with cigarette smoke status gives a highest probability to develop bladder cancer.

This combination smoking gene is biologically plausible because GSTM1 and GSTT1 genes are involved in Phase II detoxification of carcinogens PAHs found in cigarette smoke. Anyone of the two null GSTM1 or GSTT1 genotypes causes reductions of enzymatic activity $[12,13]$.

Among non-smokers group, the exposure to these carcinogens is much less important than in smokers group. Therefore, the null genotypes of GSTM1 and GSTT1 genes will have a less dangerous effect on nonsmokers group. However, in smokers, continuous exposure makes the process of detoxification that involves interventions of enzymes encoded by GSTM1 and (or) GSTT1 genes very important. Rouissi et al. [29] have noted an increased risk after the combination of many factors including GSTM1 null, GSTT1 null genotypes, and smoking. We concluded that the simultaneous association of risk factors gives a high probability to develop bladder cancer as shown by increased OR value presented in our study (OR=7.9).

On the other hand, the results of this current study indicate that there were no statistically significant associations between the clinical stages and histological grades of tumors and the frequencies of genotypes. Our findings concur with many previously published studies $[11,20,32]$.

\section{CONCLUSION}

In conclusion, our data suggest in Algerian population that GSTM1 null and GSTT1 null genotypes increase the risk for urinary bladder carcinoma. The combination of the two gene polymorphisms represents a greater risk. A strong association was found between genetic deletions of GSTM1, GSTT1, and bladder cancer among smokers. The most important risk was shown in smokers carrying double deletions of studied genes. An absence of association between GSTS genotypes, stage, and grade of tumors was registered. However, owing to the relatively smaller sample size, further studies on larger series of patients are required to confirm the present findings.

\section{ACKNOWLEDGMENTS}

The author's knowledge Pr. Nacer Balasla (Department of Urology, University Hospital of Tizi-Ouzou) and Pr. Abderrezak Dahdouh, Pr. Taoufik Djaghri (Department of Urology and renal transplantation, Daksi renal Clinic of Constantine) for their support. We would also like to thank Pr. François Radvanyi and all the staff of the Laboratory of Molecular Oncology, Institut Curie, Paris, France, for their help and assistance.

\section{AUTHORS' CONTRIBUTIONS}

All of the authors mentioned in the article have contributed to this research work. A Hireche: Protocol/project development, data collection or management, data analysis, and Manuscript writing/ 
editing. N Chaoui-Kherouatou: Protocol/project development, data analysis, Manuscript writing/editing, and final correction of the manuscript. A Ribouh: Protocol/project development and data collection or management. N Abadi: Protocol/project development. MJ Shi: Data analysis. D Satta: Protocol/project development and final correction of the manuscript.

\section{CONFLICT OF INTEREST}

The authors declare that there is no conflict of interests regarding the publication of this paper.

\section{REFERENCES}

1. Saka S, Singh AN, Sharma N. Potential anti-cancer superfoods: A minireview. Int J Curr Pharm Res 2016;8:19-21.

2. Gupta M, Dahiya J, Marwaha RK, Dureja H. Therapies in cancer treatment: An overview. Int J Pharm Pharm Sci 2015;7:1-9.

3. Ferlay J, Soerjomataram I, Ervik M, Dikshit R, Eser S, Mathers C, et al. GLOBOCAN 2012 v1.0, Cancer Incidence and Mortality Worldwide: IARC Cancer Base 2013. Available from: http://globocan.iarc.fr/. [Last accessed on 2016 may 30].

4. Hamdi Cherif M, Serraino D, Mahnane A, Laouamri S, Zaidi Z, Boukharouba $\mathrm{H}$, et al. Time trends of cancer incidence in Setif, Algeria, 1986-2010: An observational study. BMC Cancer 2014;14:637.

5. Freedman ND, Silverman DT, Hollenbeck AR, Schatzkin A, Abnet CC. Association between smoking and risk of bladder cancer among men and women. JAMA 2011;306:737-45.

6. Ferris J, Garcia J, Berbel O, Ortega J A. Constitutional and occupational risk factors associated with bladder cancer. Actas Urol Esp 2013;37:513- 22.

7. Kiriluk KJ, Prasad SM, Patel AR, Steinberg GD, Smith ND. Bladder cancer risk from occupational and environmental exposures. Urol Oncol 2012;30:199-211.

8. Burger M, Catto JW, Dalbagni G, Grossman HB, Herr H, Karakiewicz P, et al. Epidemiology and risk factors of urothelial bladder cancer. Eur Urol 2013;63:234-41.

9. Matic M, Pekmezovic T, Djukic T, Mimic-Oka J, Dragicevic D, Krivic B, et al. GSTA1, GSTM1, GSTP1, and GSTT1 polymorphisms and susceptibility to smoking-related bladder cancer: A case-control study. Urol Oncol 2013;31:1184-92.

10. Mitra AP, Cote RJ. Molecular pathogenesis and diagnostics of bladder cancer. Annu Rev Pathol 2009;4:251-85.

11. Safarinejad MR, Safarinejad S, Shafiei N, Safarinejad S. Association of genetic polymorphism of glutathione S-transferase (GSTM1, GSTT1, GSTP1) with bladder cancer susceptibility. Urol Oncol 2013;31:1193- 203 .

12. Abd El Hameed AH, Negm OE, El-Gamal OM, Hamouda HE, El Nouby KA, Ismail GM, et al. Genetic polymorphism of glutathione S-transferases M1 and T1 in egyptian patients with bilharzial bladder cancer. Urol Oncol 2010;28:296-301.

13. Song DK, Xing DL, Zhang LR, Li ZX, Liu J, Qiao BP, et al. Association of NAT2, GSTM1, GSTT1, CYP2A6, and CYP2A13 gene polymorphisms with susceptibility and clinicopathologic characteristics of bladder cancer in central china. Cancer Detect Prev 2009;32:416-23.

14. Coles BF, Morel F, Rauch C, Huber WW, Yang M, Teitel CH, et al. Effect of polymorphism in the human glutathione S-transferase A1 promoter on hepatic GSTA1 and GSTA2 expression. Pharmacogenetics 2001;11:663-9.

15. Khan AR, Taneja P. Cationic peptide lactoferricin $B$ inhibits glutathione S-transferase P1 from human placenta and breast cancer cell line MDAMB-231 preventing anticancer drog antimetabolism. Int J Pharm Pharm Sci 2015;7:238-41.
16. Malik SS, Nawaz G, Masood N. Genotypes of GSTM1 and GSTT1: Useful determinants for clinical outcome of bladder cancer in Pakistani population. Egypt J Med Hum Genet 2016. DOI:10.1016/j. ejmhg.2016.03.001.

17. Brennan P, Bogillot $\mathrm{O}$, Cordier S, Greiser E, Schill W, Vineis $\mathrm{P}$, et al. Cigarette smoking and bladder cancer in men: A pooled analysis of 11 case-control studies. Int J Cancer 2000;86:289-94.

18. Altayli E, Gunes S, Yilmaz AF, Goktas S, Bek Y. CYP1A2, CYP2D6, GSTM1, GSTP1, and GSTT1 gene polymorphisms in patients with bladder cancer in a turkish population. Int Urol Nephrol 2009;41:259- 66 .

19. Gong M, Dong W, An R. Glutathione S-transferase T1 polymorphism contributes to bladder cancer risk: A meta-analysis involving 50 studies. DNA Cell Biol 2012;31:1187-97.

20. Henriquez-Hernandez LA, Navarro P, Luzardo OP, Alvarez-Leon EE, Boarda LD, Zumbado M. Polymorphisms of glutathione S-transferase $\mathrm{mu}$ and theta, MDR1 and VEGF genes as risk factors of bladder cancer: A case-control study. Urol Oncol 2012;30:660-5.

21. Lin HJ, Han CY, Bernstein DA, Hsiao W, Lin BK, Hardy S, et al. Ethnic distribution of the glutathione transferase mu 1-1 (GSTM1) null genotype in 1473 individuals and application to bladder cancer susceptibility. Carcinogenesis 1994;15:1077-81.

22. Rouissi K, Ouerhani S, Oliveira E, Marrakchi R, Cherni L, Ben Othman F, et al. Polymorphisms in one-carbon metabolism pathway genes and risk for bladder cancer in a Tunisian population. Cancer Genet Cytogenet 2009;195:43-53.

23. Fatma B, Aida T, Maurice JA, Saguem S. Glutathione S-transferase M1 and T1, CYP1A2-2467T/delT polymorphisms and non smallcell lung cancer risk in Tunisian sample. Egypt J Med Hum Genet 2012;13:307- 12

24. Goerlitz D, El Daly M, Abdel-Hamid M, Saleh DA, Goldman L, El Kafrawy S, et al. GSTM1, GSTT1 null variants, and GPX1 single nucleotide polymorphism are not associated with bladder cancer risk in Egypt. Cancer Epidemiol Biomarkers Prev 2011;20:1552-4.

25. Nelson HH, Wiencke JK, Christiani DC, Cheng TJ, Zuo ZF, Schwartz BS, et al. Ethnic differences in the prevalence of the homozygous deleted genotype of glutathione S-transferase theta. Carcinogenesis 1995; 16:1243-5.

26. Zhang R, Xu G, Chen W, Zhang W. Genetic polymorphisms of glutathione S-transferase $\mathrm{M} 1$ and bladder cancer risk: A meta-analysis of 26 studies. Mol Biol Rep 2011;38:2491-7.

27. Sharma N, Singh A, Singh N, Behera D, Sharma S. Genetic polymorphisms in GSTM1, GSTT1 and GSTP1 genes and risk of lung cancer in a north indian population. Cancer Epidemiol 2015;39:947-55.

28. Rouissi K, Ouerhani S, Marrakchi R, Ben Slama MR, Sfaxi M, Ayed M, et al. Combined effect of smoking and inherited polymorphisms in arylamine $\mathrm{N}$-acetyltransferase 2, glutathione S-transferases M1 and T1 on bladder cancer in a Tunisian population. Cancer Genet Cytogenet 2009; 190:101-7.

29. Rouissi K, Ouerhani S, Hamrita B, Bougatef K, Marrakchi R, Cherif M, et al. Smoking and polymorphisms in xenobiotic metabolism and DNA repair genes are additive risk factors affecting bladder cancer in northern Tunisia. Pathol Oncol Res 2011;17:879-86.

30. Saad AA, O'Connor PJ, Mostafa MH, Metwalli NE, Cooper DP, Povey $\mathrm{AC}$, et al. Glutathione S-transferase M1, T1 and P1 polymorphisms and bladder cancer risk in Egyptians. Int J Biol Markers 2005;20:69-72.

31. Anwar WA, Abdel-Rahman SZ, El-Zein RA, Mostafa HM, Au WW. Genetic polymorphism of GSTM1, CYP2E1 and CYP2D6 in Egyptian bladder cancer patients. Carcinogenesis 1996;17:1923-9.

32. Kang HW, Song PH, Ha YS, Kim WT, Kim YJ, Yun SJ, et al. Glutathione S-transferase M1 and T1 polymorphisms: Susceptibility and outcomes in muscle invasive bladder cancer patients. Eur J Cancer 2013;49:3010-9. 